\title{
Reliability Prediction of Soil Humidity Sensor using Parts Count Analysis Method
}

\author{
Jaya Aggarwal and Cherry Bhargava* \\ Department of Electronics and Communication, Lovely Professional University, Jalandhar-Delhi, G.T. Road, \\ National Highway 1, Phagwara - 144411, Punjab, India; \\ jaya.aggarwal1993@gmail.com, cherry.bhargava@lpu.co.in
}

\begin{abstract}
The main objective of reliability is to determine the useful working time before which the circuit or component becomes useless. The focus in this is to understand the need to develop Artificial Intelligence technique for the determination of reliability. This is due to the fact that it serves the basic purpose of obtaining real time result for the working components and determine the time to failure to save the rest of equipment from getting affected through it. Reliability prediction of soil humidity sensor has been proposed using part count analysis method.
\end{abstract}

Keywords: Failure Rate, Humidity Sensor, Part Count Method, Reliability

\section{Introduction}

TWith advancing technology where every day new systems are being designed, functions being implemented, new equipment being used, there are increased chances for damage due to failure of equipment rather components used in making those equipment. Hence the need for reliability of these components is very high so that the system designed is trusted and reliable which can be used for longer period of time.

Moreover, if we can determine the time of failure for an equipment we can save our system by replacing those components and increase the life of system. This forms the basis of the present thesis where the main focus is on finding more accurate reliability model for components using different techniques being supplied earlier and trying to successfully implementation of those models through fuzzy logic.
As a matter of fact, there had been many traditional approaches in predicting the reliability such as MILHDBK, also the same rank has been joined by Telcordia, and PRISM. In the same race Physics of Failure also gained importance and a Modified Physics of Failure method was suggested. Still finding the scope of improvement or say implementing the method through fuzzy logic, it could give us a clear and user friendly picture of its Industrial importance ${ }^{1}$.

\section{Humidity Sensor}

Humidity is the presence of water in air. The amount of water vapor in air can affect human comfort as well as many manufacturing processes in industries. The presence of water vapor also influences various physical, chemi$\mathrm{cal}$, and biological processes. Humidity measurement in 
industries is critical because it may effect a person's health as well as degrade the product in industry.

Controlling or observing humidity is like one of the most prominent need in many Technical \& domestic applications. If we talk about semiconductor industry, then humidity or moisture scale sure to be properly controlled \& observed during silicon wafer fabrication. In medical World, humidity control is needed for respiratory equipments, Intensive Care Units, incubators, pharmaceutical processing, and Medicine or biological products 2 .

Humidity sensor is mainly of two types. Resistive sensor and capacitive sensor. By definition, relative humidity is a function of both the ambient temperature and water vapor pressure. Therefore there is a relationship between relative humidity, the amount of moisture present in the sensor, and sensor capacitance.

This relationship governs the operation of a capacitive humidity instrument. Figure of sensor with capacitive type properties is shown,

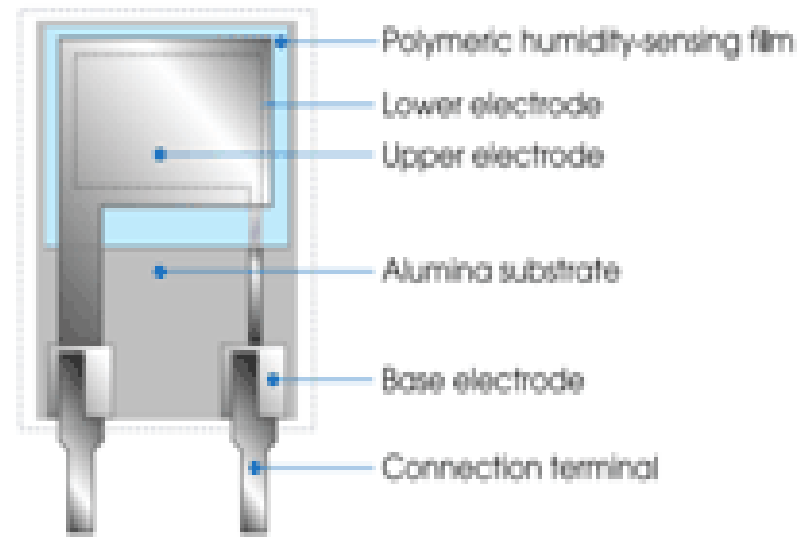

Figure 1. Capacitive humidity sensor.

Resistive type humidity sensors pick up changes in the resistance value of the sensor element in response to the change in the humidity. Structure of sensor with resistive type properties is shown in Figure 2.

Other one is thermal conductive humidity sensor. These kind of sensors the difference between the thermal conductivity of dry air and that of air containing water vapor for measuring the absolute humidity by quantifying.

Reliability of Soil humidity sensor can be predicted by taking various techniques of artificial intelligence. Here, proposed technique is using part count analysis method 3 .

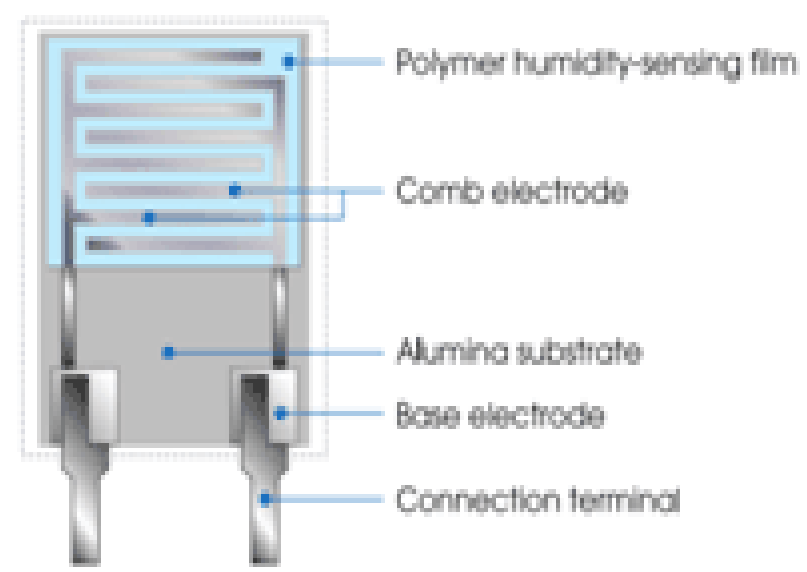

Figure 2. Resistive humidity sensor.

\subsection{Parts Count Analysis Method}

This method initially assumes typical working conditions of part or system complexity, ambient temperature, different kind of electrical stresses, operation mode and environment (called reference conditions). The failure rate for entire system is calculated with individual component or part failure rate which is calculated by using military handbook MIL-HDBK-217 and finally summing up over the range of number of components.

$$
\lambda_{b_{a} i}=\sum_{i=1}^{n}\left(\lambda_{r}\right)_{i}
$$

where: $1_{r}=$ the failure rate under the reference conditions.

There are wide range of sensors available in the market, which sense humidity. We are analyzing soil humidity sensor which is made up of few resistors, LEDs, transistor and few connectors ${ }^{4}$. 


\section{Humidity Sensor Reliability Prediction}

Reliability of Soil humidity sensor can be predicted by taking various techniques of artificial intelligence like Artificial Neural Network, Adaptive Neuro-Fuzzy Inference System, Fuzzy Logic etc Also we have various Testing methods to analyse the operation and prepare Data set out of it. Later on that can be use to predict Sensor reliability, Failure Rate and also Tool Life Here, proposed technique is using part count analysis method which is a very basic technique and mainly consider as beginner's technique for those who stated working in this field.

\subsection{Parts Count Analysis Method}

Intoduction of Part count analysis has already been given above. Considering the present work, when the humidity of any substance tends to increase, the ion concentration also increases through which the current conducted by it also increases. Basic working principle of sensing Mechanism starts from here. If there is required humidity, the current through R3 will be sufficient to produce a voltage drop across R3 which is sufficient enough $(0.7 \mathrm{~V})$ to switch on the transistor and LED glows. $\mathrm{R} 1$ is the current limiting resistor for LED. R1 protects the transistor from accidental shorting of the probes $\frac{5,6}{}$.

\subsection{Reliability Analysis of Electronic Components}

The exponential failure density function $f(t)$ is defined by (2):

$$
f(t)=\lambda e^{-\lambda t}
$$

The equation for the parts count way of predicting reliability of the soil humidity sensor activated switch is given in (3),

$$
\Lambda_{\mathrm{SHS}}=\sum_{\mathrm{i}} \lambda_{\mathrm{i}}=\mathrm{n}_{\mathrm{R}} \lambda_{\mathrm{R}}+\mathrm{n}_{\mathrm{L}} \lambda_{\mathrm{L}}+\mathrm{n}_{\mathrm{Q}} \lambda_{\mathrm{Q}}+\mathrm{n}_{\mathrm{C}} \lambda_{\mathrm{C}}+\mathrm{n}_{\mathrm{S}} \lambda_{\mathrm{S}}
$$

Where

$$
n_{R}=\text { Number of resistors in the soil humidity }
$$
sensor

$n_{L}=$ Number of capacitors in the soil humidity sensor.

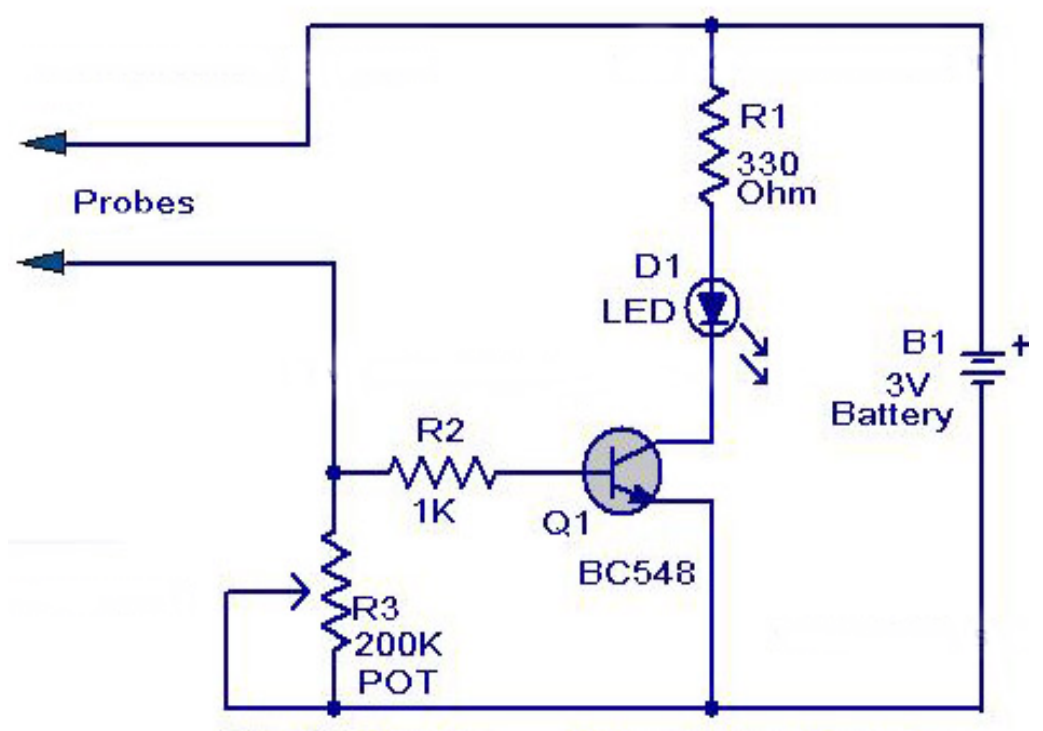

Figure 3. Soil Humidity Sensor. 
$n_{Q}=$ Number of transistors in the soil humidity sensor.

$n_{C}=$ Number of connectors in the soil humidity sensor.

$n_{S}=$ Number of switches in soil humidity sensor

$1_{R}=$ Failure rate of the resistors

$\lambda_{L}=$ Failure rate of the LED

${ }^{l_{Q}}=$ Failure rate of the transistors

$\lambda_{C}=$ Failure rate of the connector
$1_{S}=$ Failure rate of the switch

$1_{S H S}=$ Failure rate of the soil humidity sensor

By putting (3) in (2), the reliability of the soil humidity sensor is given as (4):

$$
\mathrm{R}_{S H S}(\mathrm{t})=\mathrm{e}^{-t \lambda s h s}
$$

\section{Result and Discussions}

Using part count analysis method, we can analyze the reliability of soil humidity sensor. The conclusion which we reach here is, RSHS $(t)$ of soil humidity sensor, with the normal failure rate which has been consider by taking care of the environmental factors, Table 1 and Table 2 is used to show the result we reached.

Table 1. Parts count analysis of soil humidity sensor

\begin{tabular}{|c|c|c|c|}
\hline $\begin{array}{c}\text { Components of the } \\
\text { Humidity sensor } \\
(\mathbf{a})\end{array}$ & $\begin{array}{c}\text { Quantity } \\
(\mathbf{b})\end{array}$ & $\begin{array}{c}\text { Failure rate of the } \\
\text { generic part }\left(\mathbf{1 0}^{-\mathbf{6}}\right) \\
(\mathbf{c})\end{array}$ & $\begin{array}{c}\text { Failure rate of the component } \\
\left(\mathbf{1 0}^{-\mathbf{6}}\right) \mathbf{(} \\
\mathbf{D}=(\mathbf{b})^{*}(\mathbf{c})\end{array}$ \\
\hline Resistors & 3 & 0.00370 & 0.0111 \\
\hline LED & 1 & 0.0345 & 0.0345 \\
\hline Transistors & 1 & 0.0015 & 0.0015 \\
\hline Connectors & 6 & 0.0013 & 0.0078 \\
\hline Switch & 1 & 0.1000 & 0.100 \\
\hline
\end{tabular}

Total Failure rate $=\sum(\mathrm{D})=0.1549$

Table 2. Year wise Degradation

\begin{tabular}{|c|c|c|c|c|c|}
\hline Year & 1 & 2 & 3 & 4 & 5 \\
\hline Reliability Value & 0.985 & 0.957 & 0.922 & 0.889 & 0.846 \\
\hline Year & 6 & 7 & 8 & 9 & 10 \\
\hline Reliability value & 0.803 & 0.783 & 0.728 & 0.694 & 0.647 \\
\hline
\end{tabular}

Failure Rate versus Time period: 


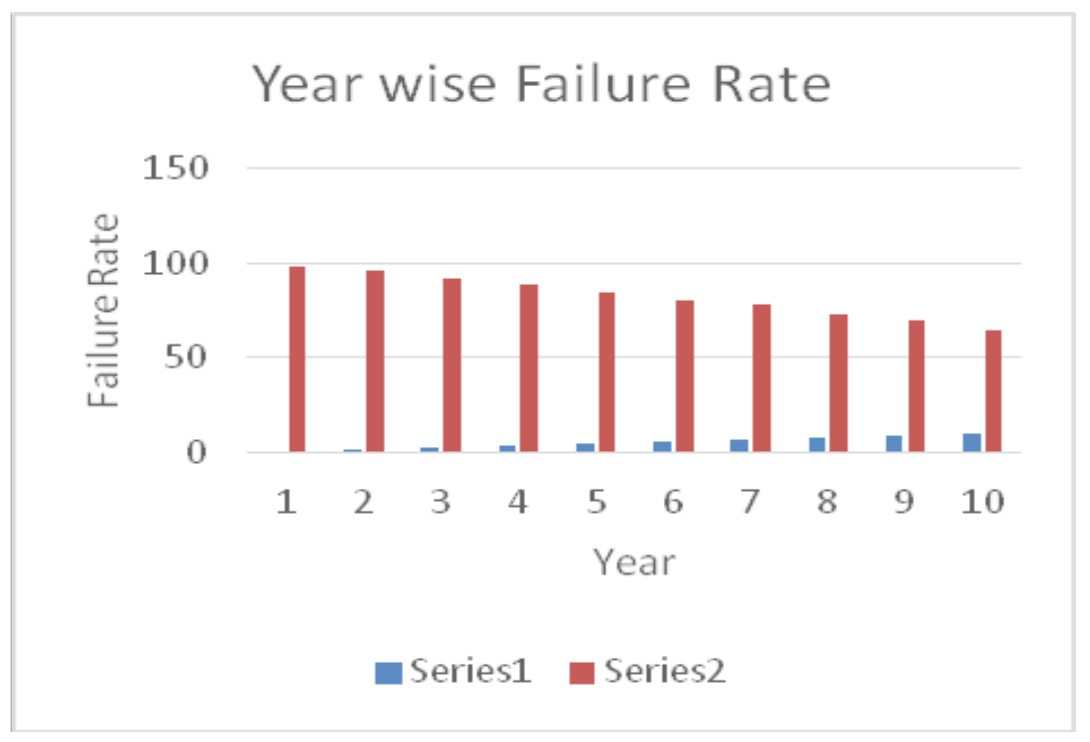

Figure 4. Failure rate versus Time period (Years).

\section{Conclusion}

With rise in technology we have to keep us in pace with it so that we could help in making progress. As the field of Artificial Intelligence is developing and very much vast, we can use it to predict reliability of system and circuit. The proposed methodology of soil humidity sensor predicts degradation value lies in between range 0.985 to 0.647 , in limit of 10 years.

\section{References}

1. Thaduri A, Gopika V, Verma AK, Gopinath R, Kumar U. Reliability prediction of semiconductor devices usingmodified physics of failure approach. Int J Syst Assur Eng Manag. 2013; 4(1):33-47.

2. Chen Z, Lu C. Humidity sensors: A review of materials and mechanism. Sensor Letters. 2005; 3(3):274-95.
3. Ramesh K, Kesarkar AP, Bhate J, Adaptive neuro fuzzy inference system for temperature and humidity profile retrieval from microwave radiometer observation. Atmos. Meas. Tech. 2015; 8:369-84.

4. Goel A, Graves RJ. Electronic System Reliability: Collating Prediction Models. IEEE Transaction on Device and Materials Reliability. 2006; 6(2):258-65.

5. Abdullahi MI, Muazu O and Jibril Y. Reliability Assessment of an Electronic System: A Case Study of a British Siren in Nigeria. Journal of Applied Sciences Research. 2007; 3(12):1671-78.

6. Bhargava C, Banga VK and Singh Y. Failure Prediction and Health Prognostics of Electronic Components: a Review. Recent Advances in Engineering and Computational Sciences. 2014; p. 1-5. 